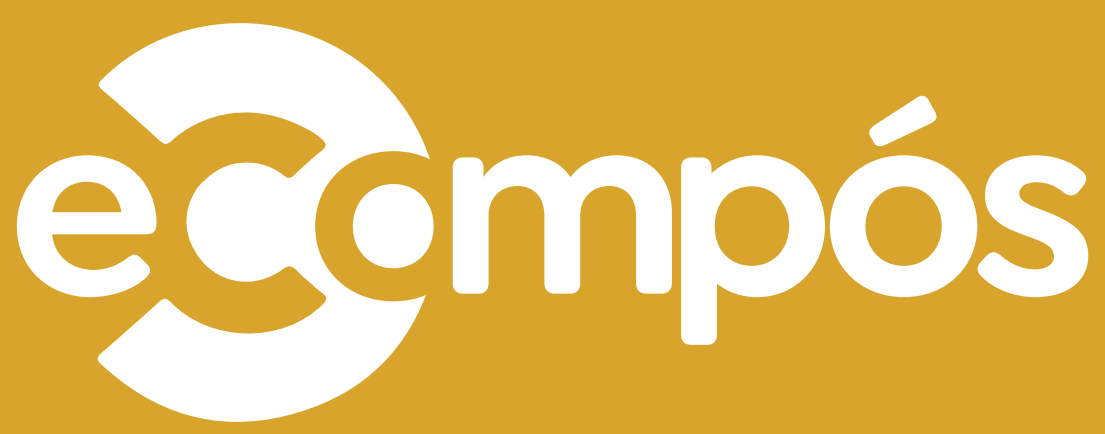

Revista da Associação Nacional dos Programas de Pós-Graduação em Comunicação

ISSN 1808-2599, v. 24, jan-dez,

publicação contínua, 2021, p. 1-18.

doi.org/10.30962/ec.2220

\title{
Valores morais em disputa entre jornalistas e não jornalistas
}

\section{DAIRAN PAUL}

Universidade Federal de Santa Catarina, Florianópolis, Santa Catarina, Brasil

\section{ROGÉRIO CHRISTOFOLETTI}




\section{/ resumo}

Atos de jornalismo são praticados por profissionais e não profissionais, o que não significa que inexistam tensões entre eles. A partir de entrevistas com sujeitos dos coletivos cariocas Carranca e Mídia Independente Coletiva, observamos como não jornalistas caracterizam seus valores morais e como avaliam os valores dos profissionais. Destacamos, ainda, como os profissionais julgam os valores dos não jornalistas. Os resultados problematizam a identidade no jornalismo e o romantismo que a caracteriza. Embora comunguem de um ethos idealizado, não jornalistas consideram que a deontologia constrange suas práticas. Profissionais, por sua vez, mobilizam virtudes próprias para autopreservar suas identidades.

Palavras-chave: Ética jornalística. Ética das virtudes. Não jornalistas. Coletivo Carranca. Mídia Independente Coletiva.

\section{Moral values in dispute between journalists and non-journalists}

Los actos de periodismo son practicados por profesionales y no profesionales, lo que no significa que no haya tensiones entre ellos. A partir de entrevistas con gente de los grupos Carranca y Mídia Independente Coletiva, desde Rio de Janeiro, analisamos cómo los no periodistas caracterizan sus valores morales y cómo evalúan los valores de los profesionales. También destacamos cómo los profesionales juzgan los valores de los no periodistas. Los resultados problematizan la identidad en el periodismo y el romanticismo que lo caracteriza. Aunque comparten un ethos idealizado, los no periodistas consideran que la deontología limita sus prácticas. Los profesionales, a su vez, movilizan sus propias virtudes para preservar sus identidades.

Palabras clave: Etica periodística. Etica de la virtud. No periodistas. Coletivo Carranca. Mídia Independente Coletiva.

\section{Valores morales en disputa entre periodistas y no periodistas}

Acts of journalism are practiced by professionals and non-professionals, which does not mean that there are no tensions between them. Based on interviews with subjects from the Rio de Janeiro collectives Carranca and Mídia Independente Coletiva, we analyzed how nonjournalists characterize their moral values and how they evaluate the values of professionals. We also highlight how professionals judge the values of non-journalists. The results problematize the identity in journalism and the romanticism that characterizes it. Although they share an idealized ethos, non-journalists consider that deontology constrains their practices. Professionals, in turn, mobilize their own virtues to self-preserve their identities.

Keywords: Journalistic ethics. Virtue ethics. Non-journalists. Coletivo Carranca. Mídia Independente Coletiva. 


\section{/ autores}

\section{ecompós}

\section{Dairan \\ PAUL}

Doutorando em Jornalismo pelo Programa de Pós Graduação em Jornalismo da Universidade Federal de Santa Catarina. Mestre pela mesma instituição. Graduado em Comunicação Social - Jornalismo pela Universidade Federal de Santa Maria (UFSM). Pesquisador do Observatório da Ética Jornalística (objETHOS - objethos. wordpress.com).

Universidade Federal de Santa Catarina, Florianópolis, Santa Catarina, Brasil.

E-mail: dairanpaul@gmail.com

\section{ORCID}

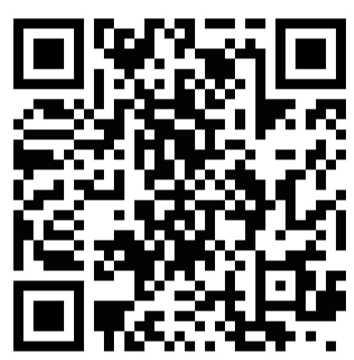

\section{Rogério CHRISTOFOLETTI}

Doutor em Ciências da Comunicação pelo Programa de Pós-Graduação em Comunicação da Universidade de São Paulo. Professor do Departamento e do Programa de Pós-Graduação em Jornalismo da Universidade Federal de Santa Catarina (PPGJOR/UFSC). Um dos coordenadores do Observatório da Ética Jornalística (objETHOS). Pesquisador do CNPq.

Universidade Federal de Santa Catarina, Florianópolis, Santa Catarina, Brasil

E-mail: rogerio.christofoletti@ufsc.br

\section{ORCID}

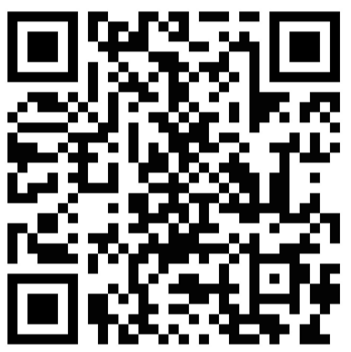




\section{Introdução}

A criação de sistemas que facilitam a publicação de conteúdos digitais e a expansão da internet permitiram mudanças tecnológicas, mas, sobretudo, transformações culturais. Conhecimento e informação foram profundamente modificados, e setores da vida social como o jornalismo foram muito impactados. Tanto é que se pode observar hoje "atos de jornalismo" praticados tanto por profissionais da área quanto por sujeitos não profissionalizados nessas práticas (STEARNS, 2013).

Estudar não jornalistas ${ }^{1}$ implica lidar com um universo vasto e heterogêneo. No que tange aos processos de produção dos sujeitos, podemos dividi-los em dois grupos: os que colaboram com veículos jornalísticos e os auto-organizados. Os primeiros participam normalmente de editorias específicas voltadas à interação com a audiência. Nesse caso, podem estar motivados pela "sensação de pertencer ao universo do jornalismo", pela partilha de valores comuns aos jornalísticos e pelo desejo de solucionar problemas sociais ao divulgarem informações às redações (SILVA; PEREIRA, 2019, p. 271).

A disposição para resolver conflitos locais também é citada por Oliveira (2013) como uma das motivações daqueles que costumavam colaborar com o jornal Diário de Pernambuco, mas demonstraram descontentamento com o processo de edição do veículo. Por isso, construíram seus próprios espaços em blogs e passaram a publicar informações apuradas por conta própria, por exemplo.

Insatisfação com a imprensa é fator comum em outra pesquisa, dessa vez de Mortensen, Keshelashvili e Weir (2015). Se, por um lado, há quem atue por "acidente" - quando estão casualmente no local de algum acontecimento e consideram relevante registrá-lo -, outros se organizam em coletivos, dispostos a apurar informações. Além da discordância com práticas da mídia mainstream, os indivíduos também aspiram a uma carreira jornalística. A motivação é igualmente identificada por Silva e Pereira (2019), mas, diferente desses autores, cujo estudo se deteve sobre sujeitos que colaboram com redações, os entrevistados de Mortensen, Keshelashvili e Weir (2015) estão auto-organizados e entram em conflito com valores deontológicos do jornalismo, como a objetividade.

Durante o mapeamento do objeto empírico deste artigo, nosso interesse de análise recaiu sobre não jornalistas que estão organizados em coletivos e não colaboram com veículos mainstream. Pressupomos, com base nos autores citados anteriormente, que uma das motivações dos sujeitos é a insatisfação com a cobertura de meios tradicionais. Nossa hipótese é que essa diferença pode se traduzir em enunciados sobre virtudes ${ }^{2}$ que tensionam valores deontológicos do jornalismo e revelam disputas morais. Portanto, a partir desse quadro, o problema do artigo questiona: com base nos discursos enunciados por jornalistas profissionais e não profissionais dos coletivos Carranca e Mídia Independente Coletiva, quais são as disputas morais em torno de virtudes sobre a prática jornalística?

Entrevistas em profundidade foram realizadas com os dois coletivos cariocas, reunindo seis não jornalistas e dois profissionais 3 . Pela amostra limitada, esta é uma pesquisa exploratória, com resultados não generalizáveis, embora contributivos. Ao final deste artigo, lançamos pistas sobre os discursos enunciados pelos dois grupos a partir de diferentes dimensões da ética - o ethos romântico, suas virtudes e seu uso estratégico.

\footnotetext{
1 Aguiar e Barsotti (2014) utilizam o termo “jornalismo amador" para definir práticas jornalísticas exercidas pelo público, em contraposição a conceitos como jornalismo participativo, colaborativo, cidadão e cívico. Embora um dos sentidos vinculados ao amador seja a dedicação a algum ofício, há também certa carga pejorativa como aquele sujeito que não domina a atividade. Não utilizamos o termo para evitar tais juízos de valor, substituindo-o pelos sinônimos "não profissional" e "não jornalista".

2 Virtudes, como discutiremos adiante, são disposições gerais cultivadas por qualquer ser humano. Pedro (2014) entende que virtude está próxima do conceito de "bem" e possui uma qualidade objetiva. "Valor" é relacional: bens e virtudes podem ser valorados, apreciados, interpretados. Utilizamos os dois termos como sinônimos (COMTE-SPONVILLE, 1999), compreendendo a virtude como um valor moral posto em ação à medida que perpassa uma subjetividade humana.

3 Os dados utilizados neste artigo resultam de uma pesquisa de dissertação de mestrado (PAUL, 2017).
} 


\section{Uma identidade instável}

Quando evitamos juízos morais sobre não profissionais, fazemo-lo porque a própria história do jornalismo evidencia o discurso ético como recorrente entre jornalistas. Durante os anos 1990, eles temiam que blogueiros proliferassem notícias mal apuradas e "roubassem" sua identidade profissional, por exemplo (SINGER, 2014). Ao menos no contexto dos Estados Unidos, essa resistência se deu até o começo dos anos 2000, quando redações passaram a incorporar o conteúdo gerado por usuários como forma de engajar a sua audiência.

Carlson (2015) entende que esse é um movimento de expansão das fronteiras jornalísticas: determinadas práticas realizadas por não jornalistas passam a ser aceitas e incorporadas, desde que não desafiem a autoridade dos profissionais. Essa assimilação, portanto, não é feita sem controles editoriais, embora costume ser celebrada como uma ode à liberdade e à participação irrestrita das audiências (MORETZSOHN, 2014).

Para ingressar no ecossistema midiático, técnicas jornalísticas são mimetizadas por não jornalistas. É uma maneira de obterem credibilidade perante o público e também serem reconhecidos como "membros" de um grupo profissional, o que poderia sinalizar para um tensionamento nas fronteiras da identidade jornalística, segundo Lopes (2013).

Partindo de uma concepção interacionista das profissões - entendendo que elas são espaço de disputa a ser conquistado -, entende-se que a identidade jornalística opera de modo fluido, na abertura e fechamento de suas fronteiras. Vinculados a diferentes trajetórias de profissionalização, os sentidos que delimitam essa identidade são negociados e reconstruídos constantemente, em contextos culturais distintos (RINGOOT; RUELLAN, 2007).

Tal processo não impede a formação de sentidos comuns sobre o que significa "ser jornalista" - é o que Deuze (2005) denomina de "ideologia ocupacional", cujos traços ideais supostamente orientariam o "verdadeiro" jornalismo. Para Hanitzsch e Vos (2017), são arranjos discursivos que têm por objetivo articular parâmetros normativos sobre a prática jornalística. Trata-se, afinal, de estratégias que mobilizam argumentos para incluir ou excluir sujeitos, em um processo de gestão das fronteiras jornalísticas de acordo com os interesses do grupo profissional.

No caso do Brasil, a formação em nível superior e o consequente diploma auxiliam tanto na profissionalização do jornalismo - a inserção no mercado de trabalho local, por exemplo - como na construção da identidade jornalística. O diploma cumpre função simbólica relevante na demarcação das fronteiras profissionais: mesmo aqueles que trabalham fora de redações ainda se autodenominam jornalistas (MICK, 2015).

Estratégias de mercado somam-se ao diploma como demarcadores simbólicos da identidade jornalística, em oposição aos não jornalistas. Folha de S. Paulo ilustra essa disputa de sentidos: o termo “jornalismo profissional" é mencionado em discurso do então diretor Otávio Frias Filho, na ocasião dos 95 anos do veículo, em 2016. Publicado ${ }^{4}$ posteriormente pelo jornal - com histórico contrário à exigência do diploma 5 -, o texto relaciona produções amadoras como sinônimas de “jornalismo comunitário", "autoral" e "militante", distintas do profissional. 
Para Oliveira (2017), esse discurso mobiliza um imaginário ancorado em valores como imparcialidade e isenção, cuja realização seria possível graças à suposta liberdade e distanciamento "inerentes" às empresas jornalísticas, de acordo com o argumento de Frias Filho. A lógica mercantil autorizaria aqueles que podem pertencer ou não ao campo jornalístico, caracterizando suas fronteiras como espaços de disputas e relações de poder.

Sentidos que correspondem ao jornalismo "militante" - como a missão na defesa de causas anticapitalistas - são próprios de uma concepção romântica do jornalismo (LAGO, 2003). No processo de renegociação de papéis da identidade jornalística, esse ethos é sobreposto por valores associados ao "jornalismo de mercado", como a objetividade. Pereira (2004) assinala que tal deslocamento acompanha a profissionalização dos jornalistas. No Brasil, ocorre a partir do Estado Novo (1937) até a aprovação da Lei de Imprensa, em 1969, resultando em mudanças nas estruturas das empresas jornalísticas e "forte ingerência estatal na organização profissional" (PEREIRA, 2004, p. 5).

\section{Ética jornalística: romântica, virtuosa, estratégica}

Se a identidade jornalística é marcada por uma coesão ilusória de valores, as normas e papéis vinculados ao ethos romântico não estão "superados" pela lógica mercantil, mas em constante disputa. Para Lago (2003), há pré-disposições românticas nos discursos da chamada imprensa alternativa, incluindo as seguintes características, conforme a autora: 1) resistência ao sistema racionalista e burocrático do capitalismo (materializada em reportagens que denunciam a alienação do trabalho, por exemplo); 2) egocentrismo que valoriza o indivíduo-criador (o "jornalista-herói"), mas, paradoxalmente, se vincula a uma comunhão coletiva (o trabalho conjunto nas redações); 3) sentido missionário de servir ao povo (o jornalismo que tem por missão vigiar os demais poderes, por compromisso aos seus leitores); 4) nostalgia e idealização do passado (quando existiria a possibilidade de intervir socialmente através do jornalismo).

Uma dimensão romântica da ética jornalística refere-se, portanto, a disposições que exaltam aspectos como "virtudes", "comprometimento" e "rigor", resumidas em uma visão de mundo utópica e combativa (LAGO, 2003, p. 4). Para a autora, os sentidos desse ethos também estão presentes em outro campo, o acadêmico - principalmente em análises que se valem de perspectivas normativas, apontam preocupações morais e prescrevem comportamentos sobre o que seria uma boa prática jornalística.

Seria possivel afirmar, então, que os sentidos do ethos romântico atravessam tanto a prática profissional de um "jornalismo virtuoso" como estudos normativos sobre ética no jornalismo. Uma chave teórica para compreender essa perspectiva é a ética das virtudes, corrente filosófica aristotélica de tradição teleológica ou seja, que entende as ações como orientadas para um fim específico, um télos. Distingue-se do pensamento kantiano, cuja doutrina da boa vontade encontra na obediência ao imperativo categórico o motivo da agência humana. Essa tradição é de origem deontológica, calcada no dever-ser, e se associa às normas, prescrições e à moral aplicada em grupos profissionais, resultando em códigos de ética (CAMPONEZ, 2009).

Especialmente a partir da segunda metade do século XX, o pensamento aristotélico é retomado por Alasdair Maclntyre (2001), por exemplo, que propõe o conceito de "prática" para abarcar o exercício das virtudes ao nivel individual. Refere-se, em suma, a quaisquer atividades humanas - um jogo de futebol, uma partida de xadrez ou o fazer jornalístico. Mas não se trata apenas de um conjunto de técnicas; há também a exigência de aceitar normas e submeter-se a um padrão de excelência. Bens internos são intrínsecos às práticas, têm o florescimento humano como finalidade e são alcançados por meio das virtudes. Já bens externos são posses individuais, rejeitam o télos comunitário do viver bem em conjunto e prescindem de virtudes.

Uma ética virtuosa perpassa sentidos do ethos romântico devido ao seu caráter eminentemente normativo - mas também pode ser utilizada como uma estratégia de autoproteção da identidade jornalística. 
Para Popescu (2013), o conjunto de virtudes intelectuais elevaria o nível de qualidade profissional do jornalismo. Afirmações como essa encontram na moral um argumento que demarca práticas jornalísticas de não profissionais - postura defensiva comum aos profissionais, como discutido anteriormente.

Nessa lógica, a busca por um jornalismo "virtuoso" se daria menos por uma questão moral e mais pela preservação de interesses, já que todo discurso seria considerado "ético" dentro dos limites que consagram o ethos de cada campo (MARTINO; MARQUES, 2018). Regras morais, portanto, seriam respeitadas porque são uma obrigação social, e não pela boa vontade do indivíduo - o desrespeito a elas implicaria colocar em xeque diferentes variáveis como prestígio do jornalista, aprovação dos pares ou mesmo lucro. Nesse sentido, recorrer a virtudes como um argumento moral de autoridade também pode representar a autoproteção da identidade dos profissionais.

\section{Procedimentos metodológicos}

Para identificar a disputa de valores morais entre jornalistas e não jornalistas, utilizamos dados coletados em Paul (2017) - a saber, entrevistas com os coletivos cariocas Carranca e Mídia Independente Coletiva (MIC). Inicialmente, mapeamos grupos de não jornalistas engajados na produção e disseminação de informações. Por se tratar de um universo vasto e heterogêneo, nos valemos de critérios para delimitar a escolha: 1) os não jornalistas não colaboram com outros veículos ${ }^{6} ; 2$ ) eles estão organizados em coletivos (ou seja, não registram acontecimentos por "acidente", de forma individual; a organização em grupos também pressupõe discussões internas sobre tomadas de decisão e possiveis dilemas morais nas suas práticas); 3) conteúdo próprio e atualizado (foram excluídos coletivos ligados à divulgação de eventos, bem como grupos que apenas replicavam materiais de outras fontes).

Em relação ao último critério, cabe salientar que tanto MIC quanto Carranca desaceleraram o ritmo de suas atividades desde a realização da pesquisa de campo, em 2017. Atualmente, seus sites estão inativos, embora suas páginas no Facebook ainda sejam mantidas. Um possivel fator para a perenidade dessas iniciativas é a condição de trabalho dos integrantes, limitada pelo fato de que coletivos não são suas ocupações principais.

O mapeamento inicial, disponivel em Paul (2017), identificou 25 grupos. Como critério final, MIC e Carranca foram selecionados pelo alto número de não jornalistas; a frequência de atualização do seu conteúdo, à época; e a rápida resposta no contato inicial que fizemos. No caso do segundo grupo, há também a presença de jornalistas, os quais também foram entrevistados. O que poderia ser um empecilho ao objetivo principal da pesquisa em Paul (2017), voltado à ética de não jornalistas, mostrou-se uma nova variável que enriqueceu os dados coletados na dissertação e deu origem às discussões presente neste artigo.

Fundada em junho de 2013 por dois cineastas e um fotógrafo, a Mídia Independente Coletiva nasce em meio aos protestos políticos que movimentaram o país naquele ano. 0 coletivo manteve um site junto de outros dois grupos cariocas - Mariachi e Rádio Mutirão. Agora, além da página no Facebook7- com 127 mil curtidas -, MIC publica matérias no Medium², embora sem a mesma frequência de atualização.

A origem do coletivo Carranca é semelhante, já que seus membros são dissidentes da Mídia Ninja - um dos principais coletivos que atuou nas Jornadas de Junho, em 2013. Carranca é fundado em setembro do mesmo ano por dez pessoas de profissões diversas, entre jornalistas, cineastas, fotógrafos e escritores.

6 Como já mencionado, pesquisas demonstram que a insatisfação com linhas editoriais é uma das possíveis motivações de não jornalistas para começarem a apurar e disseminar informações, o que pode mobilizar valores morais diferentes daqueles próprios do jornalismo que criticam.

7 Disponivel em: <https://www.facebook.com/midiaindependentecoletiva/>. Acesso em: 01 jun. 2020.

8 Disponivel em: <https://medium.com/@midiaindependentemic>. Acesso em: 29 mai. 2020. 
Atualmente, o site ${ }^{9}$ do grupo redireciona para sua página no Facebook ${ }^{10}$, que conta com nove mil curtidas.

Os participantes desta pesquisa assinaram o Termo de Consentimento Livre e Esclarecido e, embora concordassem com a exposição de seus nomes - à exceção de um entrevistado -, tiveram suas identidades preservadas por opção dos pesquisadores. Utilizamos nomenclaturas como Sujeito 1 Mídia Independente Coletiva (S1M) ou Sujeito 2 Carranca (S2C), sendo que o número se refere à ordem de realização das entrevistas. J e NJ foram acrescidos para facilitar a identificação dos jornalistas e não jornalistas.

No coletivo Mídia Independente Coletiva, entrevistamos S1M-NJ (40 anos, cineasta), S2M-NJ (47 anos, ex-estudante de administração e teatro), S3M-NJ (23 anos, estudante de direito) e S4M (41 anos, fotógrafa). Já no coletivo Carranca, participaram da pesquisa S1C-J (49 anos, jornalista), S3C-J (28 anos, jornalista), S4C-NJ (35 anos, antropólogo). S2C-NJ foi o único entrevistado que solicitou total condição de anonimato - portanto, omitiremos sua idade e profissão, bastando contextualizar, para os fins da pesquisa, que não possui graduação em jornalismo.

As entrevistas seguiram um roteiro-base que questionava os respondentes sobre o contexto de formação dos coletivos, aspectos das rotinas produtivas e os dilemas morais que surgiam na prática (PAUL, 2017). Ao total, as gravações em áudio registraram 15h20min e 220 páginas de transcrição.

Para este artigo, nos interessa observar as disputas de jornalistas e não profissionais em torno de valores morais, sejam eles deontológicos (ou seja, normatizados no jornalismo) ou não. Organizamos as diferentes percepções dos sujeitos em três eixos analíticos: 1 ) valores de não jornalistas pela perspectiva dos próprios não jornalistas; 2) valores de jornalistas pela perspectiva dos não jornalistas; 3) valores dos não jornalistas pela perspectiva dos jornalistas.

\section{Resultados}

\section{Valores morais de não jornalistas na ótica dos não jornalistas}

Neste primeiro eixo, analisamos os valores que não jornalistas atribuem a si mesmos e a outros pares sem educação formal em jornalismo. 0 objetivo é dimensionar a moral como objeto de disputa não apenas no binômio profissional e não profissional, mas entre outros coletivos.

No caso de Carranca, suas bases normativas estão atreladas à origem do grupo, formado por dissidentes insatisfeitos com a linha política e editorial da Mídia Ninja. É crítica recorrente entre os entrevistados, tanto jornalistas como não jornalistas, a falta de aprofundamento jornalístico nos ninjas. Um dos problemas era a solução que esse grupo apresentava ao discurso de isenção dos grandes jornais: a parcialidade, segundo S2C-NJ. Como sintetiza, "sou de esquerda, tenho pontos de vista específicos e isso vai transparecer no meu trabalho. Mas não quer dizer que vou produzir matérias de esquerda, defendendo pessoas de esquerda e achando que a esquerda é a única solução" (S2C-NJ).

Embora sinalizem essa preocupação, os não jornalistas do Carranca também são críticos às suas próprias parcialidades. Para S4C-NJ, a cobertura de protestos ao vivo não explorava ao máximo a contradição dos fatos, a despeito de recorrerem a fontes oficiais ligadas à polícia, por exemplo: "acho que elas sempre foram muito mais pautadas dentro dessa visão de que éramos poucos e tínhamos que dar voz aos oprimidos, e não aos opressores" (S4C-NJ). A relação ambígua com fontes também atravessa práticas da Mídia Independente Coletiva, ora acarretando erros de apuração, ora se aproximando do cuidado como uma virtude que tensiona normas da deontologia jornalística (PAUL; CHRISTOFOLETTI, 2020).

9 Disponivel em: <http://coletivocarranca.cc/>. Acesso em: 01 jun. 2020.

10 Disponivel em: <https://www.facebook.com/coletivocarranca/>. Acesso em: 01 jun. 2020. 
Transmissões ao vivo de protestos também motivaram outras tensões entre os não jornalistas, especialmente sobre quais imagens deveriam ser mostradas. S4C-NJ argumenta que parte das filmagens poderia ser classificada como sensacionalista, já que manifestantes "às vezes começavam a depredar muito mais coisa porque tinha uma mídia gravando".

MIC estabeleceu a segurança de quem protestava como critério sobre o que poderia ser filmado. S3M-NJ afirma que o compromisso do coletivo é com os sujeitos que participam dos protestos - a foto em boa qualidade é secundária. S1M-NJ também ressalta que é prática proibida a filmagem por motivos apenas estéticos, como manifestantes incendiando lixeiras, principalmente se ele puder ser reconhecido posteriormente por policiais que acessarem o arquivo das transmissões.

Essa norma que orienta coberturas ao vivo do coletivo é implementada depois que manifestantes foram identificados em transmissões e passaram a ser perseguidos. Anteriormente, os entrevistados relembram que a ideia era filmar o máximo de conteúdo possível. "Tinha uma coisa espetaculosa, de ver as pessoas reagindo - porque isso realmente tem uma emoção representativa" (S2M-NJ).

S4M-NJ também reconhece o sensacionalismo inicial nas transmissões da MIC, especialmente porque fotos e vídeos com fogos atraíam curtidas e compartilhamentos nas redes sociais. Para a entrevistada, essa contrapartida impulsionava ainda mais a prioridade ao estético, e seria fruto de um "deslumbramento" no universo midiativista, seja pela aspiração a uma carreira jornalística, por questões individuais ou mesmo pela possibilidade de lucrar a partir das publicações. S1M-NJ compartilha dessas impressões e considera que alguns ativistas envolvidos em coletivos "gostam de aparecer", desejando estar ao vivo "o tempo todo". Nesse sentido, os dois entrevistados apontam o dinheiro como uma possivel interferência no conteúdo de alguns coletivos. É uma "forma de abafar", de tornar o discurso "mais frouxo", sintetiza S4M-NJ.

\section{Valores morais de jornalistas na ótica dos não jornalistas}

Divergências em relação às práticas de outros não jornalistas, especialmente aqueles que atuavam na Mídia Ninja, servem de norte para o trabalho do coletivo Carranca. O zelo pela checagem de informações e uma maior profundidade no estilo de texto - investindo em reportagens, e não apenas em publicações em forma de nota nas redes sociais - seriam preocupações centrais do grupo, segundo S2C-NJ.

No entanto, mesmo que esse discurso prevaleça nas demais entrevistas com não jornalistas do coletivo, nem sempre eles se mostram dispostos a cumprir procedimentos técnicos e éticos do jornalismo. Ao escrever suas matérias, o antropólogo S4C-NJ afirma considerar mais importante investir na qualidade de "bons argumentos" do que na "materialidade dos fatos", nos "dados que corroboravam" a situação apresentada. A preferência era interpelada por jornalistas do Carranca, que questionavam se as informações do texto foram exaustivamente checadas, ou se havia fotos e vídeos que as comprovassem.

Cobranças desse tipo efetuadas por profissionais contribuíram para um sentido comum encontrado nas respostas dos não jornalistas: a percepção dos procedimentos e normas do jornalismo como um "engessamento" de suas práticas. Um exemplo que ilustra esse atrito é a organização do Carranca, quando todos os seus integrantes passaram a trabalhar como editores. Em um primeiro momento, qualquer matéria deveria receber dois votos favoráveis antes de ser publicada no site do grupo. Devido à demora nas respostas - por falta de tempo e de compromisso, como admite S2C-NJ -, o novo critério para subir textos passou a ser subjetivo e individual, baseado na confiança entre os membros. S2C-NJ relata que essa mudança acirrou embates entre valores morais de jornalistas e não jornalistas:

Como era um grupo muito heterogêneo, as pessoas divergiam. E tinha a S1C-J, que era jornalista. [...] discutindo com cara que não era jornalista. Ela tinha toda uma coisa da ética jornalística, 'o que devo falar, o que não devo falar, tenho que checar isso'. Aí você fala com um cara que acha que não deve fazer isso. [...] Aí é briga. (S2C-NJ). 
Assim como na Mídia Independente Coletiva, as transmissões ao vivo também eram fonte de conflito no Carranca. S4C-NJ relata discordâncias entre jornalistas e não jornalistas sobre o "papel" que deveria ser desempenhado pelo coletivo, o que está relacionado às finalidades normativas e, portanto, aos valores de suas práticas:

Você tinha jornalistas do grupo que ficavam tentando entender: ‘afinal, que p... é essa desses anarquistas e black blocs?'. [...] Ficava nessa discussão sobre como as pessoas que estavam fazendo essa cobertura iriam agir. [...] As votações aconteciam nesses momentos de tensões muito éticas: 'e aí, vou filmar ou não vou filmar a pessoa quebrando?' [...] Você tinha pessoas que eram mais da ponta do movimento, que não eram nem jornalistas, e defendiam essa ação direta, essa proposta de derrubar os símbolos do capitalismo. [...] E você tinha os jornalistas, que estavam lá tentando falar: ‘não, não é esse o nosso papel. Nosso papel é registrar o que está acontecendo na rua, e não falar se essa ação é boa, legítima ou não'.

Embates como esses apontam, no caso do Carranca, que não jornalistas reconhecem valores morais específicos do jornalismo, e que nem todos estão dispostos a cumprir procedimentos técnicos e éticos da profissão. Na síntese de S2C-NJ, "ser jornalista dá trabalho". Nesse sentido, profissionais parecem ocupar uma posição específica no coletivo voltada à checagem de informações.

Na Mídia Independente Coletiva, a ética jornalística também é entendida como um engessamento na atuação dos não jornalistas. Esse sentido emerge quando S1M-NJ afirma que "o jornalismo ainda está preso a certas normas" e a um "modelo de representação institucional limitador". o jornalismo "de redação", nas palavras do entrevistado, não teria maleabilidade suficiente para manter uma postura ética democrática na defesa de camadas populares, ao lado de sujeitos vulneráveis que não têm voz para contar suas histórias. Segundo o participante, essa seria a principal diferença da MIC para o jornalismo mainstream: "nós podemos ser mais contundentes".

Os não jornalistas da MIC também reconhecem virtudes na prática jornalística, embora seus discursos enfatizem a fragilidade dessas normas por interferências externas. S4M-NJ elogia a técnica do lead porque refina o texto - "coisas que o pessoal que não é jornalista não sabe" -, mas ressalta que linhas editoriais orientadas ao lucro podem corromper as virtudes do jornalismo. Essa perspectiva é compartilhada por S1M-NJ, quando o sujeito se refere ao contato que tem com jornalistas da mídia mainstream: "eles estão limitados pelo poder das redações, pelo interesse financeiro. E eles admitem isso. O cara fala 'eu tô aqui pra ganhar o meu dinheiro, mas isso é uma vergonha. Eu sinto vergonha do que está sendo feito"' (S1M-NJ).

Através dessas falas, os não jornalistas da MIC ilustram como o télos do jornalismo molda práticas. Como já discorremos, elas possuem bens internos específicos - as virtudes, que almejam a excelência e são cultivadas em estruturas sociais como a organização jornalística. Bens externos abrigados nessas instituições podem corromper virtudes e distinguir o télos do florescimento humano (MACINTYRE, 2001) para outras finalidades. Um exemplo seria a fama, rejeitada pelos membros da MIC: "a gente não tá buscando essa mídia glamourosa, cheia de prêmios" (S2M-NJ).

Esse trecho também demarca um esforço dos não jornalistas para se distanciarem das práticas realizadas nas grandes redações, o que também é perceptível na denominação que atribuem aos seus coletivos. Apenas S3M-NJ menciona a palavra "jornalismo", ao dizer que exerce um "jornalismo crítico". Seus colegas, e também no caso de Carranca, utilizam outros termos como midiativismo ou mídia alternativa.

No entanto, quando questionados sobre os valores que defendem em suas práticas, não jornalistas recorrem àqueles normatizados no jornalismo. Busca pela verdade, defesa de direitos humanos, sigilo e respeito por fontes são alguns exemplos. Paradoxalmente, embora busquem demarcar uma posição diferente do que compreendem por jornalismo, há uma aproximação no conjunto de valores quando não jornalistas argumentam sobre suas práticas. 
Mais especificamente, há um atravessamento de sentidos do ethos romântico do jornalismo no discurso dos não jornalistas. Essa pré-disposição é identificada tanto em Carranca como em Mídia Independente Coletiva, especialmente em trechos que abordam a motivação dos sujeitos: "eu falo que a gente é um pouco médico: deu um lance e a gente tem que sair, tentar resolver e externar essa indignação" (S1M-NJ); "fiquei na casa dele virando a madrugada, escrevendo o texto e publicando a primeira matéria" (S3M-NJ); "foi o que realmente tomou a minha vida [...]. É vício, entendeu?" (S2C-NJ); "lutar por uma causa é uma coisa que é muito mais, digamos, uma vontade, uma necessidade" (S4M-NJ); "2014 foi um ano de intenso trabalho, de virar noite fazendo coisas" (S4C-NJ); "agora a gente tá um pouco suave, mas no início eram 12 horas dentro do computador - e aí você fica tão imerso nessa situação que você já está ali absorvido, permeado" (S2M-NJ).

As falas recuperam duas características do ethos romântico: dedicação a uma causa - a defesa pelos direitos humanos e grupos vulneráveis, por exemplo - e o sentido missionário de suas práticas. Os não jornalistas entrevistados sentem necessidade de testemunhar acontecimentos, apurar pautas emergenciais e resolver conflitos. Essa urgência - que entende o trabalho como prazeroso e viciante, embora exaustivo - pode ser explicada pelo cruzamento sugerido por Träsel (2014) do ethos romântico com a ética hacker, ilustrada pelo pesquisador no jornalismo de dados. Um dos valores comuns aos dois conjuntos seria a paixão e dedicação intensa a uma atividade. Pela perspectiva dos hackers, se trata de celebrar o ócio criativo e criar uma oposição moral à lógica protestante do trabalho (HIMANEN, 2002). No caso de nossos entrevistados, a participação nos coletivos ocorre quando dispõem de tempo livre e chega a ser extenuante - embora, paradoxalmente, confira sentido à vida social dos sujeitos e lhes dê satisfação.

\section{Valores morais de não jornalistas na ótica de jornalistas}

Se alguns valores do ethos romântico atravessam de forma homogênea as práticas dos coletivos - como a paixão e intensa dedicação pelo trabalho -, outros podem conflitar com a ética circunscrita ao domínio profissional do jornalismo. Nesse eixo analisaremos as disputas morais pela ótica dos jornalistas na sua relação com não jornalistas.

Um dos primeiros impasses que seguiram à fundação de Carranca era a sua autoimagem institucional: eles eram um coletivo de jornalismo ou um movimento social? Os dois não jornalistas do coletivo tinham entendimento diferente de seus outros colegas não profissionais. Para S2C-NJ, "algumas pessoas queriam que Carranca fosse um movimento político, e eu não acho que a função de um movimento é informar. É informar, mas sobre o próprio movimento, e não sobre as coisas que estão acontecendo". S4C-NJ concorda:

\footnotetext{
Sempre achei que a gente era mídia alternativa, mas acho que o entendimento de vários colegas que estavam lá é de que éramos midiativismo. De chegar e produzir denúncia com movimentos sociais (S4C-NJ).
}

Essa rejeição à ideia de que Carranca era um movimento social foi reforçada pelos jornalistas do grupo. S3C-J diz que sempre se viu como parte de um coletivo de jornalismo. S1C-J, por sua vez, explica que a finalidade do Carranca não era servir de propaganda para atos políticos. Em sua argumentação, podemos observar uma demarcação inicial entre jornalistas - sujeitos racionais que não apenas relatam, mas analisam fatos - e não jornalistas - mobilizados pela paixão, com técnica limitada.

Na tentativa de se diferenciar do Mídia Ninja, Carranca nasce com a proposta de oferecer análises mais densas para acontecimentos. Contudo, a relação entre profissionais e não profissionais dentro do grupo é permeada por disputas de valores que ora reforçam a deontologia do jornalismo, por parte dos profissionais, ora questiona sua pertinência, no caso de alguns não jornalistas. 
S1C-J relembra uma matéria assinada por não jornalistas sobre a morte de Gleise Nana, manifestante conhecida por denunciar publicamente ações violentas da Polícia Militar. À época, a suspeita era de um incêndio criminoso no apartamento da vítima, já que Nana era vigiada e perseguida por PMs. Segundo avalia o entrevistado da pesquisa, o texto escrito pelos não jornalistas atendia a padrões formais de estilo jornalístico, mas carecia de fontes como o delegado do caso, Polícia Militar, o advogado de Gleise Nana ou familiares da vítima. A matéria também sugeria correlações entre o crime e a PM, embora não apresentasse provas. Pela falta de dados, o "projeto de notícia" - assim denominado por S1C-J - não foi publicado no site do coletivo.

De forma geral, a entrevistada considera que não jornalistas têm menos apego a procedimentos como checagem de informações e contato com fontes oficiais. "Ele é levado [a agir] por impulso, porque aquilo ali [o acontecimento] é uma aberração, e ele acha que tem que ser divulgado. Eles não apuram, simplesmente replicam" (S1C-J). S3C-J reitera essa percepção, mas acrescenta que fontes oficiais não costumam responder mídias alternativas, embora a dificuldade não justifique deixar de contatá-las. "Acho mais honesto você colocar, mesmo que seja diante de gente que você não gosta, do que fazer de conta que eles não existem" (S3C-J). Para S1C-J, a preocupação com fontes oficiais acabou se tornando um diferencial do Carranca, já que "ninguém [dos outros coletivos] confirmava com a Polícia Federal".

O sensacionalismo nas transmissões ao vivo também foi um tópico discutido pelos jornalistas. S3C-J admite certa irritação quando assistia coberturas realizadas por não jornalistas:

Eu não gosto porque, bem, eu sou jornalista, e as pessoas que faziam, no geral, não tinham essa formação, e não tinham o que ficar falando. É que nem rádio: você não pode 'deixar silêncio' - só que as pessoas não 'deixavam silêncio' falando um monte de baboseira (S3C-J).

Recorre-se, na justificativa do entrevistado, ao estatuto profissional como posição de autoridade dotada de um saber específico. 0 argumento remete não apenas a um conjunto de procedimentos técnicos, mas também a valores morais - já que a finalidade das práticas é moldada conforme a pré-disposição ao cultivo das virtudes.

\section{Considerações finais}

Nas fronteiras fluidas que caracterizam a identidade jornalística, movimentos de expansão convidam novos atores a integrar a área - mas raramente concedem-lhes a mesma posição de poder e controle dos profissionais. Esse argumento é reforçado por uma expertise específica que dota jornalistas de um saberfazer próprio. Contudo, procedimentos técnicos são também éticos à medida que valores morais sedimentam práticas, pois apontam para uma finalidade e também servem de pré-disposição para a sua efetividade.

Em outras palavras, e conforme tratamos neste artigo, o cultivo de virtudes no âmbito do jornalismo seria pré-requisito para alcançar níveis de excelência com vista a um télos, a uma finalidade específica. Essa lente teórica evoca sentidos de um ethos romântico e normativo sobre como a prática jornalística deve ser. Quando Popescu (2013) afirma que virtudes elevariam a própria qualidade "profissional" do jornalismo, podemos interpretar que elas também cumprem uma função simbólica em demarcar jornalistas - aqueles aptos à prática virtuosa - de não jornalistas.

Nos dois coletivos analisados, podemos observar diferentes disputas morais entre os grupos. o primeiro eixo de análise identificou tensões entre os próprios não jornalistas de Carranca e Mídia Independente Coletiva. Um dos temas mais recorrentes nas respostas foi o sensacionalismo, aspecto que tangenciou a cobertura de protestos dos coletivos. Membros da MIC admitem que já priorizaram a estética de fotos e vídeos em detrimento da identificação de manifestantes ou mesmo da apuração de mais dados. 
Contudo, mudaram a atitude após debates internos. No caso do Carranca, não jornalistas são críticos às suas próprias parcialidades e nem sempre conseguiram explorar a contradição dos fatos, conforme relatam, devido à escolha por priorizar fontes não-oficiais.

Tal dificuldade está relacionada ao que Harcup (2015) chama de "moral própria" nos coletivos alternativos às mídias mainstream, sintetizada na máxima: "Dar voz aos que não têm voz". Em pesquisa anterior, discutimos como a virtude do cuidado enunciada pelos não jornalistas, posta em prática na escolha - por vezes única - de fontes que pertencem a grupos socialmente vulneráveis, conflita com valores dentológicos do jornalismo, como o equilíbrio, e acarretam até mesmo erros de informação, como já relataram os membros de MIC (PAUL; CHRISTOFOLETTI, 2020).

Em uma leitura geral das mídias alternativas, Harcup (2015) também considera que elas não privilegiam mecanismos que formalizam diretrizes e parâmetros éticos, como códigos internos. Costa, Araújo e Lima (2020) chegam a essa conclusão quando constatam a baixa visibilidade que arranjos alternativos de jornalismo, no estado do Ceará, dedicam à explicitação de seus valores e normas para o leitor. Esse aparente rechaço da dimensão deontológica não significa que inexistam discussões internas sobre ética entre os membros dos coletivos, mas nos auxilia a compreender um dado que constatamos nas respostas: a compreensão da deontologia jornalística como um "engessamento" às práticas dos não profissionais.

No segundo eixo, identificamos disputas sobre os valores entre jornalistas e não jornalistas, sob a ótica dos dois grupos. No caso dos não profissionais, membros do Carranca reconhecem a importância de normas no jornalismo, mas consideram que o excesso de checagens ou mesmo a comprovação de dados por fotos ou vídeos acabam impedindo a publicação de informações que eles parcialmente apuram. Já integrantes não jornalistas da MIC compreendem que valores deontológicos do campo podem impedir uma atuação mais contundente dos profissionais na defesa de populações vulneráveis, em uma possível alusão à objetividade jornalística. Por outro lado, quando não jornalistas dos dois grupos são questionados sobre a definição de suas práticas - se são movimento social, coletivo de jornalismo etc. -, recorrem a valores próprios do jornalismo nas justificativas, como busca pela verdade e defesa dos direitos humanos.

O sentido de defesa por uma causa específica, somado às respostas que relacionam o trabalho nos coletivos a uma "missão" ou "vício", é como o ethos romântico se mostra mais evidente nos enunciados dos não jornalistas dos dois coletivos analisados. Já nos jornalistas do Carranca, se liga ao jornalismo que é possivel de ser feito fora de estruturas convencionais. S3C-J, por exemplo, diz que "o jornalismo corporativo perverte isso [a independência e a liberdade] a favor de interesses que não são os mesmos da ética jornalística".

Assim, o ethos romântico atravessa profissionais como um atenuante ao "sofrimento ético" (LELO, 2019) que lidam em experiências anteriores - ou seja, quando seus valores morais conflitam com os daqueles onde estão empregados. Os resultados, embora não possam ser generalizáveis devido ao caráter exploratório da pesquisa, dialogam com outros estudos. Na pesquisa de Deuze e Witschge (2020) com 22 coletivos internacionais, os entrevistados entendem o jornalismo como um "projeto passional", a despeito de suas condições precárias de trabalho. Conclusão semelhante à de Fígaro, Barros e Kinoshita (2019), com novos arranjos alternativos de jornalismo em São Paulo: a vontade de exercer o jornalismo que se acredita é posta em xeque pelas formas de sustentação dos grupos. Por fim, Silva (2017) também identifica certo romantismo em uma análise específica de dois coletivos paulistas, entrevistando membros que entendem o jornalismo como algo artesanal, próximo de uma forma de arte. Contudo, apesar de uma suposta ruptura de valores com aqueles próprios de estruturas convencionais das redações jornalísticas, a autora considera que coletivos também refletem disputas internas e diferentes hierarquizações de poder.

São diferenças que também verificamos nos enunciados dos respondentes de Carranca e Mídia Independente Coletiva. A particularidade dessa pesquisa, no entanto, é identificar que embora os dois grupos comunguem de um ethos romântico, disputas morais ainda ocorrem no interior dos coletivos. Como o estatuto 
profissional de jornalistas perpassa o controle de fronteiras, é o discurso deontológico que alicerça uma base supostamente segura para o grupo conseguir se diferenciar e excluir os não profissionais (PEREIRA, 2008).

Já o terceiro eixo de análise identifica a disputa moral entre jornalistas e não jornalistas pela ótica dos profissionais. Embora também estejam afetados pelo ethos romântico, jornalistas do coletivo Carranca buscam se diferenciar dos não jornalistas enunciando seus valores como mais racionais e menos mobilizados pela defesa apaixonada de causas. Convergem, portanto, para um arranjo discursivo sobre papéis e normas que devem ser desempenhados por eles, os profissionais, sinalizando virtudes próprias (os valores deontológicos) e um discurso de autodefesa da identidade jornalística (delimitada pelo ethos dos agentes). As respostas ainda revelam o discurso da ética como "estratégia de garantia de legitimidade" (MARTINO, 2010, p. 38), quando o ajuste às regras do campo jornalístico - as normas, cristalizadas na sua deontologia - compensa um lucro simbólico aos jornalistas, como o prestígio entre pares e a demarcação das fronteiras perante não profissionais.

O ethos romântico do jornalismo atravessa os dois coletivos analisados de formas distintas, portanto. No caso dos profissionais de Carranca, está atrelado a uma dimensão estratégica e relacionada à ética jornalística, conformando valores deontológicos às suas práticas. Não jornalistas de Carranca e MIC, por sua vez, compartilham de virtudes como a prática combativa e anticapitalista dos valores românticos, entendendo que possuem a "missão" de proteger e dar voz a grupos socialmente vulneráveis. No entanto, não estão necessariamente dispostos a cultivar virtudes próprias da prática jornalística, especialmente por compreenderem a deontologia como um engessamento de suas atuações. Ainda que demarquem uma posição moral de contraste aos jornalistas - o que também ocorre por parte dos profissionais -, não jornalistas reconhecem que eles possuem especificidades técnicas e éticas.

O cenário que descrevemos neste artigo apresenta mais uma vez que produtores e consumidores de informação se misturam, colidem ou trabalham em conjunto a partir de fronteiras profissionais e éticas cada vez mais borradas. Partindo de um estudo exploratório com dois coletivos, e considerando as limitações de alcance da pesquisa, nosso artigo identificou disputas morais entre jornalistas e não jornalistas que compartilham relativamente dos mesmos valores românticos. Contudo, não profissionais idealizam a prática jornalística apenas sob determinados parâmetros normativos e conflitam com valores deontológicos. Já os jornalistas constroem para si a imagem de profissionais orientados por uma racionalidade técnica (ao contrário dos não profissionais "passionais"), acompanhada de discursos sobre preocupações éticas em suas práticas. Esses tensionamentos não só ilustram as disputas morais, mas também exibem dinâmicas cada vez mais comuns nos processos de comunicação. Se nos debruçamos sobre dois coletivos brasileiros, outros pesquisadores poderão verificar a ocorrência comum em outras geografias, o que sinaliza a necessidade de novos estudos futuros.

Conforme discutimos em trabalho anterior (PAUL; CHRISTOFOLETTI, 2020), há um conjunto de autores que sustentam bases morais comuns a jornalistas e não jornalistas. Também apontamos dificuldades no engajamento de não profissionais em discussões éticas sobre o jornalismo (CHRISTOFOLETTI, 2014), o que exige disposição de setores, empresas e jornalistas na abertura da "caixa-preta" sobre o fazer jornalístico. Neste artigo, avançamos um pouco mais e adicionamos novas camadas à discussão, incluindo dados empíricos que tensionam a proposta de uma "ética aberta" (WARD; WASSERMAN, 2010) entre jornalistas e não jornalistas. 0 argumento desenvolvido até aqui objetiva contribuir aos estudos em ética jornalística pela sua particularidade: as disputas morais entre profissionais e não profissionais perduram mesmo entre aqueles que compartilham de idealizações românticas sobre o jornalismo e atuam de forma colaborativa. De forma adicional, esperamos também ter contribuído para revelar algumas sutilezas da apropriação de valores de terceiros e da reafirmação desses mesmos valores em contextos ainda pouco conhecidos e documentados. Investigações com populações mais generosas e com intervalos de tempo mais amplos são necessárias e bem-vindas para aprofundar nosso entendimento sobre essa arena moral. 


\section{Referências}

AGUIAR, Leonel; BARSOTTI, Adriana. Jornalismo amador: proposta para definir as práticas jornalísticas exercidas pelo público em ambientes interativos. Pauta Geral - Estudos em Jornalismo, v. 1, 46-61, 2014.

CAMPONEZ, Carlos. Fundamentos de deontologia do jornalismo: a auto-regulação frustrada dos jornalistas portugueses (1974-2007). 2009. 583 f. Tese (Doutorado em Ciências da Comunicação) - Universidade de Coimbra, 2009.

CARLSON, Matt. Introduction. The many boundaries of journalism. In: CARLSON, Matt; LEWIS, Seth (Eds.). Boundaries of journalism: professionalism, practices and participation. New York: Routledge, 2015.

CHRISTOFOLETTI, Rogério. Preocupações éticas no jornalismo feito por não jornalistas. Comunicação \& Sociedade, v. 25, p. 267-278, 2014.

COMTE-SPONVILLE, André. Pequeno tratado das grandes virtudes. São Paulo: Martins Fontes, 1999.

COSTA, Rafael Rodrigues da; ARAÚJO, Mayara Carolinne Beserra de; LIMA, Raphaelle Christine Batista de. Apontamentos para um perfil dos arranjos alternativos de jornalismo no Ceará. Cambiassu, v. 15, n. 25, 2020.

DEUZE, Mark; WITSCHGE, Tamara. Da suspeita ao encantamento na pesquisa em jornalismo. Esferas, n. 17, 2020.

. What is journalism? Journalism, v. 6, n. 4, p. 442-464, 2005.

FÍGARO, Roseli; BARROS, Janaina; KINOSHITA, Jamir. As relações de comunicação e as condições de produção no trabalho de jornalistas em arranjos econômicos alternativos às corporações de mídia. In: ENCONTRO NACIONAL DE PESQUISADORES EM JORNALISMO, 17., 2019, Goiânia. Anais... São Paulo: SBPJor, 2019.

HANITZSCH, Thomas; VOS, Tim. Journalistic roles and the struggle over institutional identity: the discursive constitution of journalism. Communication Theory, v. 27, n. 2, 2017.

HARCUP, Tony. Listening to the voiceless: the practices and ethics of alternative journalism. In: ATTON, Chris (Ed.). The Routledge Companion to alternative and community media. Routledge: New York, 2015. p. 313323.

HIMANEN, Pekka. La ética del hacker y el espírito de la era de la información. Trad. Ferran Meler Ortí. Barcelona: Destino, 2002.

LAGO, Cláudia. De romântico e de louco... Reflexões sobre o romantismo jornalístico. In: ENCONTRO ANUAL DA COMPÓS, 12., 2003, Recife. Anais... São Paulo: Compós, 2003.

LELO, Thales Vilela. O sofrimento ético no mundo do trabalho dos jornalistas. E-Compós, v. 23, p. 1-20, 2019. 
LOPES, Fernanda Lima. Ser jornalista no Brasil: identidade profissional e formação acadêmica. São Paulo: Paulus, 2013.

MACINTYRE, Alasdair. Depois da virtude: um estudo em teoria moral. Bauru: Edusc, 2001.

MARTINO, Luís Mauro Sá. Ética como discurso estratégico no campo jornalístico. Líbero, v. 13, n. 26, p. 31-38, 2010.

; MARQUES, Ângela Cristina Salgueiro. Ética, mídia e comunicação: relações sociais em um mundo conectado. São Paulo: Summus, 2018.

MICK, Jacques. Trabalho jornalístico e convergência digital no Brasil: um mapeamento de novas funções e atividades. Pauta Geral, v. 2, n. 1, p. 15-37, 2015.

MORETZSOHN, Sylvia. O 'jornalismo cidadão' e o mito da tecnologia redentora. Brazilian Journalism Research, v. 10, p. 248-271, 2014.

MORTENSEN, Tara; KESHELASHVILI, Ana; WEIR, Tom. Who we are: a study of types of citizen journalists. Digital Journalism, v. 3, n. 4, p. 1-20, 2015.

OLIVEIRA, Michelle Roxo de. Por onde passam as fronteiras do jornalismo profissional? Estratégias de distinção de um jornal-empresa a partir da emergência de novos atores e meios produtivos. Comunicação Midiática, v. 12, n. 2, p. 101-114, 2017.

OLIVEIRA, Sheila Borges de. 0 repórter-amador: uma análise das disposições sociais motivadoras das práticas jornalísticas do cidadão comum. 2013. 327 f. Tese (Programa de Pós-Graduação em Sociologia) Universidade Federal de Pernambuco, Recife, 2013.

PAUL, Dairan. Valores morais em atos de jornalismo: reflexões sobre uma ética para não jornalistas. 2017. 472 f. Dissertação (Programa de Pós-Graduação em Jornalismo) - Universidade Federal de Santa Catarina, 2017.

. ; CHRISTOFOLETTI, Rogério. Cuidado, virtude e dilemas morais nas práticas de não jornalistas. Intercom - Revista Brasileira de Ciências da Comunicação, v. 43, p. 21-36, 2020.

PEDRO, Ana Paula. Ética, moral, axiologia e valores: confusões e ambiguidades em torno de um conceito comum. Kriterion, n. 130, p. 483-498, 2014.

PEREIRA, Fábio Henrique. Os jornalistas-intelectuais no Brasil: identidade, práticas e transformações no mundo social.468 f. Tese (Programa de Pós-Graduação em Comunicação) - Universidade Federal de Brasília, Brasília, 2008.

Da responsabilidade social ao jornalismo de mercado: o jornalismo como profissão. Biblioteca

On-line de Ciências da Comunicação, Corvilhã, 2004. Disponivel em: <http://www.bocc.ubi.pt/pag/pereirafabio-responsabilidade-jornalista.pdf>. Acesso em: 16 jan. 2020. 
POPESCU, Victor. Bloggers, journalists and epistemic responsibility. A particular type of self-regulation in the Romanian online media. In: INTERNATIONAL CONFERENCE ON MEDIA ETHICS, 2., 2013, Sevilha. Anais... University of Seville: School of Communication, p. 110-122, 2013.

RINGOOT, Roselyne; RUELLAN, Denis. Journalism as permanent and collective invention. Brazilian Journalism Research, v. 3, n. 2, p. 67-76.

S1C [pseudônimo]. Entrevista III. [mai 2017]. Entrevistador: Dairan Paul. Rio de Janeiro, 2017. 1 arquivo .mp3 (338 min.). S2C [pseudônimo]. Entrevista V. [mai 2017]. Entrevistador: Dairan Paul. Rio de Janeiro, 2017. 1 arquivo .mp3 (118 min.). S3C [pseudônimo]. Entrevista VI. [mai 2017]. Entrevistador: Dairan Paul. Rio de Janeiro, 2017. 1 arquivo .mp3 (73 min.). S4C [pseudônimo]. Entrevista VIII. [mai 2017]. Entrevistador: Dairan Paul. Rio de Janeiro, 2017.1 arquivo .mp3 (76 min.). S1M [pseudônimo]. Entrevista I. [mai 2017]. Entrevistador: Dairan Paul. Rio de Janeiro, 2017. 1 arquivo .mp3 (69 min.). S2M [pseudônimo]. Entrevista II. [mai 2017]. Entrevistador: Dairan Paul. Rio de Janeiro, 2017. 1 arquivo .mp3 (75 min.). S3M [pseudônimo]. Entrevista IV. [mai 2017]. Entrevistador: Dairan Paul. Rio de Janeiro, 2017. 1 arquivo .mp3 (65 min.). S4M [pseudônimo]. Entrevista VII. [mai 2017]. Entrevistador: Dairan Paul. Rio de Janeiro, 2017. 1 arquivo .mp3 (98 min.). SINGER, Jane. Sem medo do futuro: ética do jornalismo, inovação e um apelo à flexibilidade. Comunicação e Sociedade, v. 25, p. 49/67-66/82, 2014.

SILVA, Mariana da Rosa. Tensões entre o alternativo e o convencional: organização e financiamento nas novas experiências de jornalismo no Brasil. 2017. 396 f. Dissertação (Programa de Pós-Graduação em Jornalismo) - Universidade Federal de Santa Catarina, Florianópolis, 2017.

SILVA, Marcelli; PEREIRA, Fábio. O percurso do amador para integrar notícia televisiva: as motivações e modalidades de cooperação no telejornalismo brasileiro. Razon y Palabra, v. 23, n. 104, 2019.

STEARNS, Josh. Acts of Journalism: defining Press Freedom in the Digital Age. [S. l.]: Free Press, 2013.

TRÄSEL, Marcelo. Entrevistando planilhas: estudo das crenças e do ethos de um grupo de profissionais de jornalismo guiado por dados no Brasil. 2014. 311 f. Tese (Programa de Pós-Graduação em Comunicação e Informação) - Universidade Federal do Rio Grande do Sul, Porto Alegre, 2014.

WARD, Stephen; WASSERMAN, Herman. Towards an open ethics: implications of new media platforms for Global Ethics Discourse. Journal of Mass Media Ethics: exploring questions of media morality, v. 25, n. 4, p. 275-292, 2010. 


\section{Informações para textos em coautoria}

\section{Concepção e desenho do estudo}

Dairan Paul; Rogério Christofoletti

\section{Aquisição, análise ou interpretação dos dados}

Dairan Paul

\section{Redação do manuscrito}

Dairan Paul; Rogério Christofoletti

\section{Revisão crítica do conteúdo intelectual}

Rogério Christofoletti

\section{Informações sobre 0 artigo}

\section{Resultado de projeto de pesquisa, de dissertação, tese}

0 artigo integra resultados da dissertação de mestrado "Valores morais em atos de jornalismo: reflexões sobre uma ética para não jornalistas", defendida no Programa de Pós-Graduação em Jornalismo (PPGJOR/UFSC).

\section{Fontes de financiamento}

Dairan Paul foi bolsista CAPES - Processo 1545584 durante a realização desta pesquisa.

\section{Considerações éticas}

Avaliado e aprovado pelo Comitê de Ética em Pesquisa da Universidade Federal de Santa Catarina. Número do parecer: 2.143.664.

\section{Declaração de conflito de interesses}

Não se aplica.

\section{Apresentação anterior}

Não se aplica.

\section{Agradecimentos/Contribuições adicionais}

Agradecemos à CAPES por financiar a pesquisa da qual originou este artigo, e aos pareceristas da E-Compós pelas contribuições à versão final. 